\title{
Increasing Use of Disease Modifying Drugs for MS in Canada
}

\author{
Dalia L. Rotstein, Muhammad Mamdani, Paul W. O’Connor
}

\begin{abstract}
Background/Objectives: The course of multiple sclerosis may be slowed by use of the disease modifying drugs (DMDs): subcutaneous or intramuscular interferon beta-1a, interferon beta-1b, glatiramer acetate, and natalizumab. We set out to compare utilization of these drugs in the Canadian provinces from 2002-2007. Methods: Using a retrospective cohort analysis, we reviewed population data from International Medical Statistics (IMS) Health between November 2001 and October 2007. Results: The total annual number of DMD prescriptions increased from 3.9, in 2002, to 5.1, in 2007, per 1,000 Canadians. The total annual cost of prescriptions rose from $\$ 187$ million to $\$ 287$ million. Of the four provinces responsible for the majority of prescriptions - Alberta, BC, Ontario, and Quebec Quebec had the highest average annual prescription rate (7 per 1,000 population) and BC had the lowest rate (3.3 per 1,000 population). Subcutaneous interferon beta-1a was the most commonly used drug whereas glatiramer acetate showed the greatest growth in use from 2002 to 2007. Conclusions: Disease modifying drugs prescription rates and costs increased by more than $30 \%$ between 2002 and 2007. There was wide variation in DMD prescription rates and relative drug preferences across the provinces.
\end{abstract}

\begin{abstract}
RÉSUMÉ: Utilisation croissante des médicaments modificateurs de la maladie dans le traitement de la sclérose en plaques au Canada. Contexte et objectifs : L'utilisation de médicaments modificateurs de la maladie (MMM) administrés par voie parentérale pour traiter la sclérose en plaques peut ralentir l'évolution de la maladie : l'interféron bêta-1a, l'interféron bêta-1b, l'acétate de glatiramère et le natalizumab. Le but de notre étude était de comparer l'utilisation de ces médicaments dans les provinces canadiennes entre 2002 et 2007. Méthodes : Nous avons révisé les données de population de l'International Medical Statistics (IMS) Health entre novembre 2001 et octobre 2007 au moyen d'une analyse de cohorte rétrospective. Résultats : Le nombre annuel total de prescriptions de MMM a augmenté de 3,9 par 1000 Canadiens en 2002 à 5,1 en 2007. Le coût annuel total des prescriptions a augmenté de $\$ 187$ millions à $\$ 287$ millions. Parmi les quatre provinces responsables de la majorité des prescriptions - l'Alberta, la Colombie-Britannique, l'Ontario et le Québec - le Québec avait le taux moyen annuel de prescription le plus élevé (7 par 1000 de population ) et la Colombie-Britannique le taux le plus bas (3,3 par 1000 de population). Le médicament le plus utilisé était l'interféron bêta-1a par voie sous-cutanée alors que le médicament dont l'utilisation avait accusé la plus forte croissance de 2002 à 2007 était l'acétate de glatiramère. Conclusions : Les taux de prescription de MMM et les coûts ont augmenté d'à peu près $30 \%$ de 2002 à 2007 . Il existe une grande variation dans les taux de prescription et les préférences relatives pour ces médicaments selon les provinces.
\end{abstract}

Can. J. Neurol. Sci. 2010; 37: 383-388

Multiple sclerosis (MS) is an inflammatory central nervous system disease associated with a variable degree of neurologic dysfunction brought on by both relapses of the disease and more chronic progressive neurologic deterioration. While there is no cure for MS, there are several "disease modifying" drugs (DMDs) that have been shown to reduce the number of relapses, slow the progression of disability, and decrease the rate of growth in the cranial magnetic resonance imaging (MRI) lesion burden over time. ${ }^{1}$ These medications include subcutaneous (sc)interferon beta-1a (Rebif), intramuscular (im) interferon beta-1a (Avonex), sc interferon beta-1b (Betaseron), sc glatiramer acetate (Copaxone), and intravenous natalizumab (Tysabri).
Interferon beta-1b was approved for relapsing-remitting MS in Canada in 1995, glatiramer acetate in 1997, both formulations of interferon beta-1a in 1998, and natalizumab in 2006. Dosing frequency ranges from daily for glatiramer acetate to monthly for natalizumab. There is no evidence of a significant efficacy

From the Division of Neurology, St. Michael's Hospital, University of Toronto, Toronto, Ontario, Canada.

Received July 22, 2009. Final Revisions Submitted December 22, 2009 Correspondence to: Paul O'Connor, 30 Bond Street, Suite 3-007 Shuter Wing, St. Michael's Hospital, Toronto, Ontario, M5B 1W8, Canada. 
difference between interferon-beta and glatiramer acetate although their side-effect profiles differ somewhat. ${ }^{2}$ Both classes of drugs are safe overall with no evidence of long-term toxicity. Natalizumab, a selective adhesion molecule inhibitor with arguably greater efficacy and potential toxicity, was introduced in 2006. ${ }^{3}$ It is recommended in Canada for patients with relapsing-remitting MS who have already failed therapy with one of the older immune modulating agents or who have particularly aggressive early disease. ${ }^{4}$

The use of DMDs in Canada is of major importance both because of the high prevalence of MS in Canada (at 240 per 100,000 in 2005) and the high associated costs of the disease. ${ }^{5}$ In contrast, in the United States, the prevalence of MS in 2002 was estimated at 85 per $100,000 .{ }^{6}$ With its high prevalence, MS also poses a particularly heavy human cost to society in Canada as it often leads to individual suffering, disability, lost employment, and stranded dependents, and often strikes people, especially women, in the prime of life. ${ }^{7,8}$ The DMDs mitigate the disease and ensuing disability, but because of their high cost they also pose a significant economic burden to Canadian society. Each of the four first-line DMDs costs approximately $\$ 20,000$ in Canada annually. The provinces have different guidelines governing the funding of these agents, and these provincial programs involve a varying degree of cost sharing by patients.

We set out to determine how DMD prescription rates and costs have changed with time, both provincially and nationally.

\section{METHODS}

We examined observational cohort data from Canada for prescription numbers and expenditures on the DMDs from November 2001 to October 2007. Data was available for the ten Canadian provinces, but not for the two territories, the Yukon and the Northwest Territories. Each calendar year was defined as November in the preceding year through October of the given year (i.e. when referring to "2002," the data were taken from November 2001 to October 2002). The data were provided by the Canadian CompuScript Audit of IMS Health Canada.

CompuScript monitors retail pharmacies for the number and costs of prescriptions dispensed monthly. Costs refer to net costs and do not reflect any subsidies that might have been offered to individual consumers. Data were collected from a respresentative sampling of more than 2,100 retail pharmacies across Canada; stratified by region, size, and type of outlet; then projected by CompuScript to derive provincial estimates. Prescription numbers were tracked using a consistent standard for unit volume data.

CompuScript does not collect data from in-hospital prescriptions, although in-hospital DMD prescriptions are exceedingly rare in Canada by virtue of the high DMD costs.

The data from IMS Health is commonly used by various government and private bodies interested in prescription rates. ${ }^{9}$ No data is available through CompuScript on the demographic attributes of patients receiving these prescriptions.

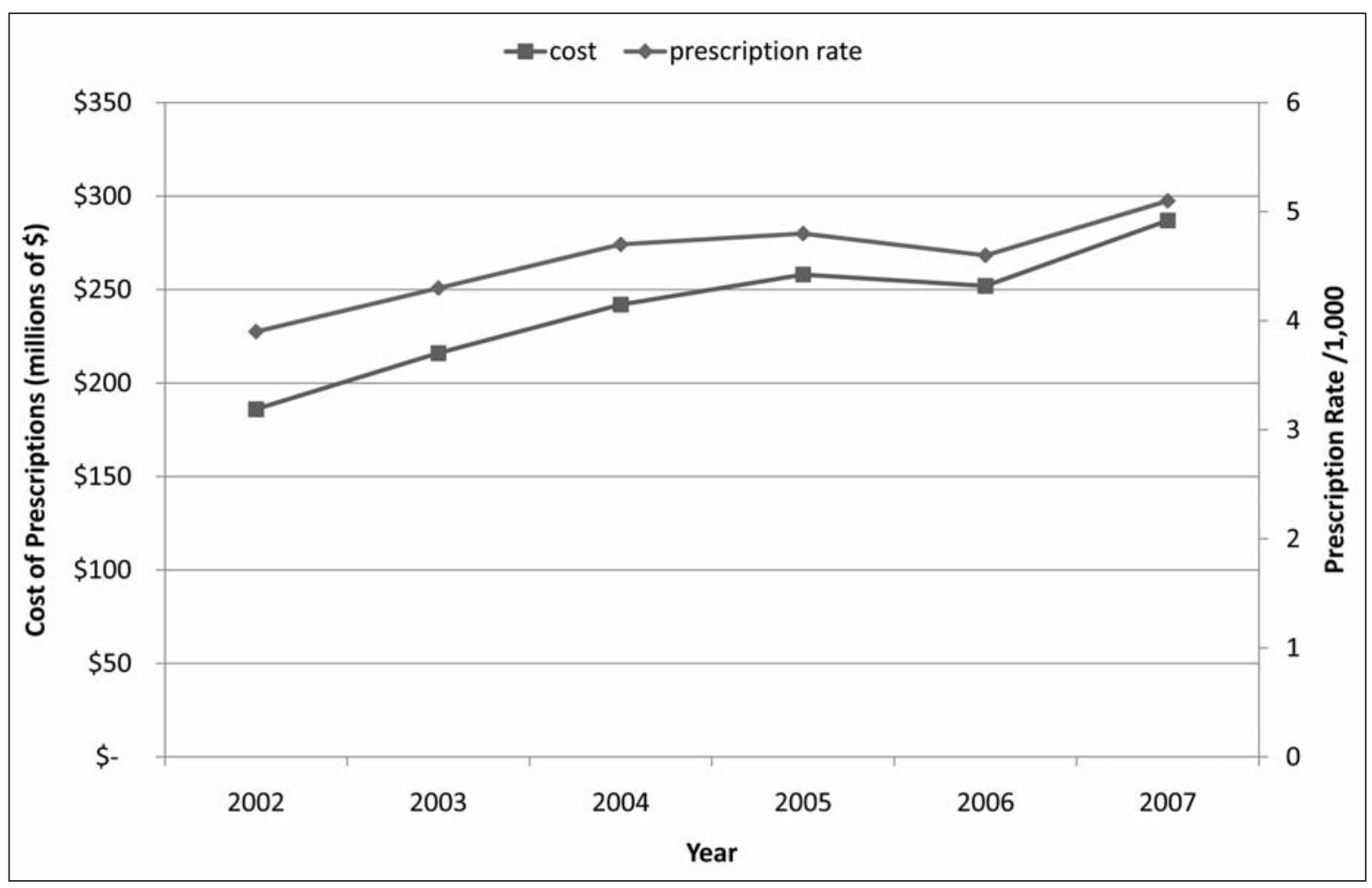

Figure 1: Monthly DMD Prescriptions in Canada, 2002-2007. Data represent the annual number of prescriptions per 1000 population and the annual cost in millions of dollars. Data were from the Canadian CompuScript Audit of IMS Health Canada. Population estimates were from the Census of Canada. 
Population figures were obtained from the Census of Canada. ${ }^{10}$ We derived data looking at prescription numbers per capita, and then stratified results by province and drug type. Subcutaneous interferon beta-1a numbers included both low and high dose formulations of the product.

\section{RESULTS}

From 2002 to 2007, the total annual DMD prescription rate in Canada increased from 3.9 to 5.1 per 1,000 (Figure 1). The total cost of DMDs in Canada increased from \$187 million in 2002 to $\$ 287$ million in 2007 - an increase of $53 \%$. Ontario and Quebec accounted for the greatest number of prescriptions, 60-63\% of total national prescriptions in each year of the study (Table). Their share of prescriptions was approximately equal to their share of the population, 62.4-62.6\% (excluding the Territories). Prescribing rates for DMDs varied widely between the provinces, including within a single region. The Maritimes included the province with the highest prescription rate, New Brunswick, and the province with the lowest prescription rate, Nova Scotia. The total number of prescriptions in the four most populous provinces, which account for the majority of DMD prescriptions, is illustrated in Figure 2. The province of Quebec accounted for the greatest absolute number of DMD prescriptions in 2007, despite the fact that its population was 7.7 million people compared to Ontario's 12.8 million in 2007. British Columbia and Ontario had consistently lower prescribing rates than either Alberta or Quebec.

Figure 3 shows Canadian national prescription rates from 2002-2007 grouped by drug. Interferon beta-1a (Rebif) was the most commonly prescribed agent during this period overall and, in particular, in British Columbia, Ontario, and Quebec. The volume of glatiramer acetate prescriptions grew the most between 2002 to 2007 , increasing from 0.9 to 1.4 prescriptions per 1,000. Glatiramer acetate was the drug most commonly prescribed in Alberta and Saskatchewan in 2002, remaining in that position through to 2007. Intramuscular interferon beta-1a (Avonex) showed considerable growth in prescriptions over this period although it began at a much lower base. Interferon beta$1 \mathrm{~b}$ was the only drug with an overall decline, although slight, from 1.02 to 0.97 prescriptions per 1,000 between 2002 and 2007. Natalizumab usage is not depicted because the only data available on its use prior to 2008 is from Quebec, where there were 397 prescriptions in 2007 or five prescriptions per 100,000 people.

\section{Discussion}

There has been an approximately $30 \%$ increase in the rate of DMD prescriptions and an almost $50 \%$ increase in the total cost of prescriptions in Canada since 2002. No new DMDs entered the market during this period, with the exception of natalizumab, which was rarely used due to lack of any provincial funding. The proliferation in prescriptions may be partially attributable to the release of new clinical trials supporting the DMDs and the revision of clinical guidelines in their wake.

For example, during this time there was growing evidence that patients with first demyelinating events or clinically isolated syndromes (CIS) could benefit from treatment with intramuscular interferon beta-1a. ${ }^{11,12}$ Previously most neurologists did not treat MS unless there was clinical evidence of multiple attacks. The Controlled High Risk Avonex Multiple Sclerosis Study (CHAMPS) study indicated that intramuscular interferon beta-1a reduced conversion from CIS to clinically

Table: Total annual DMD prescriptions by region

\begin{tabular}{|c|c|c|c|c|c|c|c|c|}
\hline & 2002 & 2003 & 2004 & 2005 & 2006 & 2007 & $\begin{array}{r}\text { \% of Total } \\
\text { Prescriptions } \\
\text { in } 2007\end{array}$ & $\begin{array}{r}\text { Prescription } \\
\text { Rate in 2007 } \\
(/ 1,000) \\
\end{array}$ \\
\hline Alberta & 14,028 & 16,327 & 17,952 & 18,328 & 15,914 & 19,144 & 11.4 & 5.5 \\
\hline BC & 12,642 & 12,610 & 14,119 & 15,093 & 14,948 & 14,497 & 8.6 & 3.3 \\
\hline Manitoba & 6,140 & 7,545 & 11,035 & 11,421 & 10,250 & 10,725 & 6.4 & 9.0 \\
\hline Saskatchewan & 4,312 & 4,876 & 5,396 & 5,848 & 6,544 & 7,278 & 4.3 & 7.3 \\
\hline $\begin{array}{l}\text { Western } \\
\text { Canada Total }\end{array}$ & 37,122 & 41,358 & 48,502 & 50,690 & 47,656 & 51,644 & 30.7 & 5.1 \\
\hline $\begin{array}{l}\text { New } \\
\text { Brunswick }\end{array}$ & 4,270 & 5,560 & 6,200 & 6,459 & 6,441 & 7,421 & 4.4 & 9.9 \\
\hline Nova Scotia & 1,464 & 1,542 & 1,592 & 1,672 & 1,378 & 1,839 & 1.1 & 2.0 \\
\hline PEI/NFLD & 2,055 & 1,931 & 2,326 & 2,397 & 2,695 & 3,267 & 1.9 & 5.1 \\
\hline $\begin{array}{l}\text { Maritimes } \\
\text { Total }\end{array}$ & 7,789 & 9,033 & 10,118 & 10,528 & 10,514 & 12,527 & 7.5 & 5.4 \\
\hline Ontario & 36,188 & 40,178 & 43,202 & 44,025 & 41,647 & 49,847 & 29.7 & 3.9 \\
\hline Quebec & 39,838 & 46,285 & 48,295 & 48,949 & 51,186 & 53,947 & 32.1 & 7.0 \\
\hline Canada Total & 120,937 & 136,854 & 150,117 & 154,192 & 151,003 & 167,965 & 100 & 5.1 \\
\hline
\end{tabular}

PEI $=$ Prince Edward Island NFLD = Newfoundland 


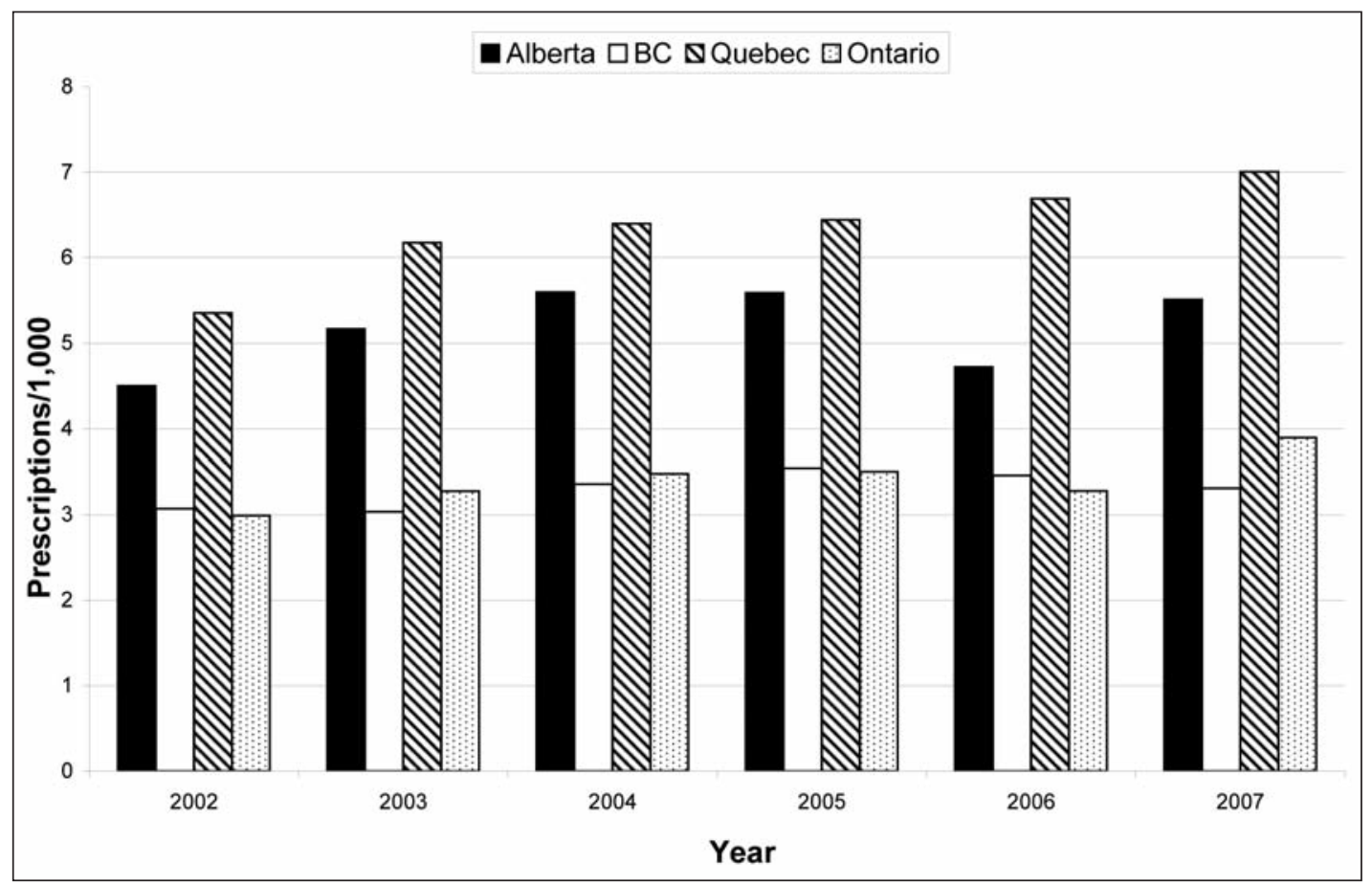

Figure 2: Rate of Annual DMD Prescriptions for the Four Most Populous Provinces: Alberta, BC, Quebec, Ontario. The total DMD prescription rate for each province is plotted by year. Prescription numbers were from the Canadian CompuScript Audit of IMS Health Canada. Provincial population numbers were from the Census of Canada.

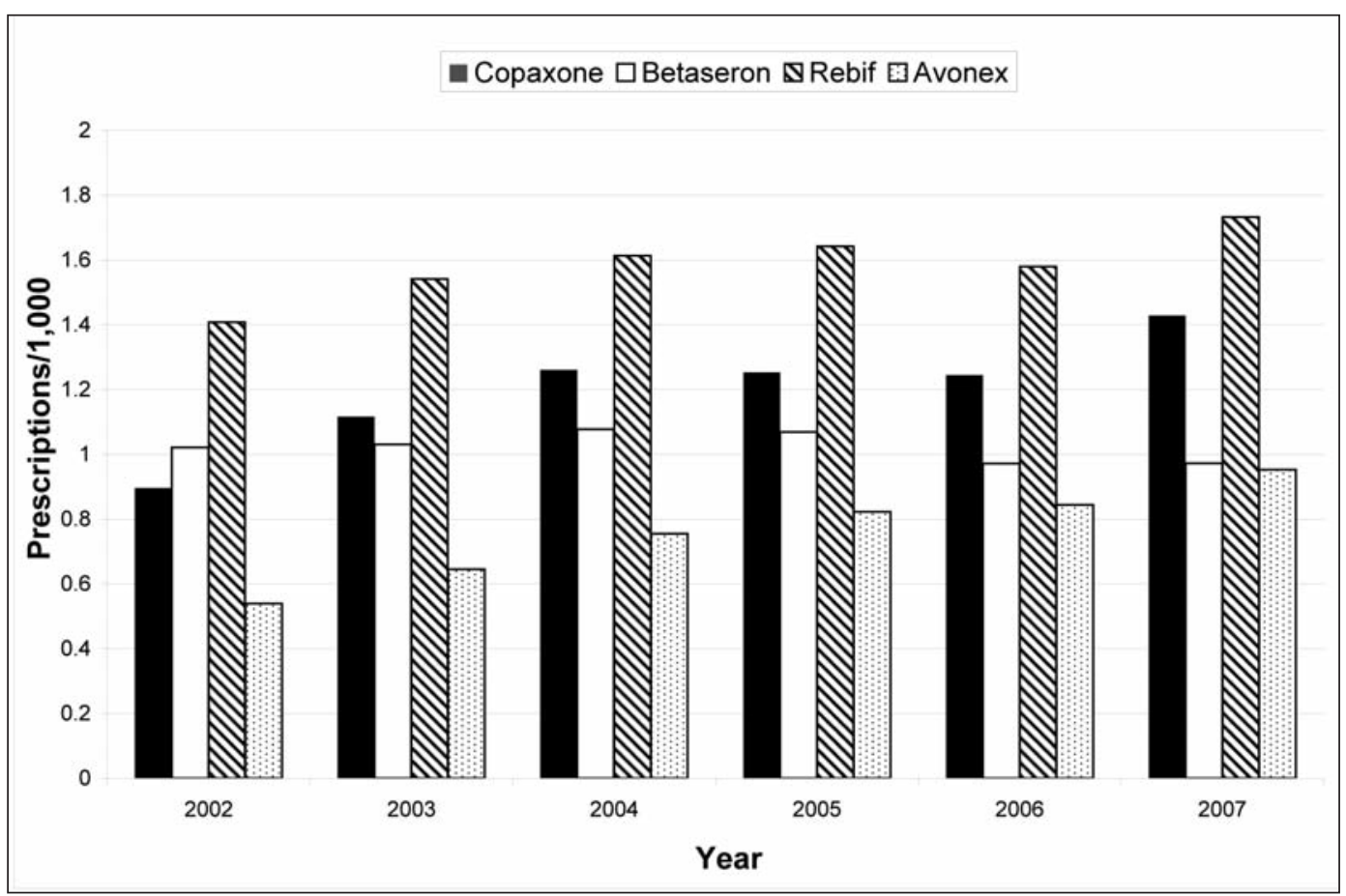

Figure 3: DMD Annual Prescription Rates in Canada, 2002-2007, by Drug Type. Prescription numbers per 1,000 population are represented. Prescriptions numbers were from the Canadian CompuScript Audit of IMS Health Canada and annual population from the Census of Canada. The drug types are Copaxone (glatiramer acetate), Betaseron (interferon beta-1b), Rebif (interferon beta-1a), and Avonex (intramuscular interferon beta-1a). 
definite MS by $44 \%$ at three years, with favourable MRI findings as well. ${ }^{11}$

Following CHAMPS, various professional associations of neurologists, including the American Academy of Neurologists (AAN), revised their guidelines to include CIS as an indication for treatment. ${ }^{4,13}$ Patient advocacy groups, the foremost being the Multiple Sclerosis Society of Canada, have educated MS patients about these advances. This effort has been assisted by the expansion in medical imaging capacity. The total number of MRI scanners in Canada has increased from 146 in 2003 to 196 in 2006 (no data were available for 2002 and 2007). ${ }^{14}$ Magnetic resonance imaging can facilitate the diagnosis of CIS and earlier diagnosis of MS. The wider availability of MRI could have led to increased prescription rates particularly in the context of CIS being newly identified as an indication for treatment.

An example of how negative clinical results can affect prescription rates is provided by interferon beta- $1 \mathrm{~b}$. The European study in secondary progressive MS suggested that interferon beta-1b was of benefit over placebo in treating secondary progressive MS, which had no record of effective treatments to date. ${ }^{15}$ Interferon beta-1b prescription rates rose, albeit slightly, in Canada in the aftermath of this study, between 2002 and 2004. In 2004, the North American trial in secondary progressive MS was published which contradicted the previous study by showing no benefit of interferon beta-1b over placebo. ${ }^{16}$ Interferon beta- $1 \mathrm{~b}$ usage rates then declined in the ensuing years from 2005 through 2007.

Yet these factors (clinical trials, MRI scanners and neurologists) are unlikely by themselves to account for the growing popularity of the DMDs. The pharmaceutical industry has likely played a role both directly through its efforts to educate neurologists and indirectly through its support of advocacy groups such as the MS Society of Canada. The pharmaceutical industry's influence may help to explain, as well, provincial differences between preferred DMDs. A recent study showed an association between American academic physicians who receive grant support from pharmaceutical companies and their prescriptions of DMDs manufactured by the same company. ${ }^{17}$ Similar data is not available for DMD-prescribing neurologists in Canada although it would be of interest. In this study we observed that glatiramer acetate has been relatively frequently prescribed in Alberta and Saskatchewan from the onset of its availability. Glatiramer acetate maintained its advantage in these provinces over time, demonstrating the longterm impact that early capture of market share can yield on prescribing patterns and the consistency of prescribing patterns over time.

Similarly, while prescribing patterns varied, sometimes markedly, between provinces, such patterns tended to remain consistent within a province between 2002 and 2007. For example, despite having less than two-thirds the population of Ontario, Quebec was responsible for more DMD prescriptions than Ontario in each of the years reviewed. There may be several explanations for the consistency in these interprovincial differences. First, the guidelines governing provincial funding for such agents differ by province. In British Columbia and Manitoba prescriptions are only accepted when written by neurologists working in specialized MS clinics; in most provinces, any neurologist can write a DMD prescription. (In some provinces, non-neurologists are permitted to write DMD prescriptions, but the clinical detail required to meet provincial reimbursement requirements typically necessitates a neurologist's exam).

Moreover, the strictness of the criteria used to determine whether a particular patient is eligible for provincial reimbursement (number of relapses, MRI findings, and so on) varies between provinces. In British Columbia and Ontario, where reimbursement rules are relatively detailed and restrictive, DMD prescribing rates are lower. In Quebec, the reimbursement rules are less rigid and prescribing rates are higher.

Second, the degree of patient copayment seems to influence DMD use. Disease modifying drugs entail a cost of approximately $\$ 20,000$ annually and are therefore unaffordable for many without comprehensive drug coverage. All of the Canadian provinces have a plan to aid patients with DMD costs, but the generosity of such plans varies. In Quebec, where high prescription rates prevailed, maximum annual patient contributions are capped, regardless of individual income. In other provinces copayments are calculated on the basis of annual income and are not capped. Indeed, the lack of provincial financial support for natalizumab has controlled its use in Canada such that in 2007, the first year that it was federally approved for use, there were fewer than 400 prescriptions on record.

It is difficult to account for how the prevalence of MS may have varied over time and between provinces. There is little information about how prevalence has changed over time. A study of MS prevalence in Alberta revealed a prevalence of 2.18 per 1,000 in 1990 that rose to 3.58 in 1,000 by $2004 .{ }^{18}$ The authors attributed this effect to an improved life expectancy of those with the disease and to an increased disease incidence. Another important factor affecting prevalence may be the growing public and physician awareness of MS, fostered by pharmaceutical companies, MS advocacy groups, wider access to MRI scanners, and an increasing concentration of neurologists per capita.

There have been several studies that have attempted to quantify the prevalence of MS by province. A study using data from the Canadian Community Health Survey, a national, crosssectional survey, found 332 subjects with self-reported MS out of 116,109 participants in 2000-2001. These results gave the estimated overall prevalence of MS of 2.40 per 1,000 in Canada. ${ }^{5}$ Of the five regions studied (Atlantic Canada, Quebec, the Prairies, BC, and Ontario), prevalence ranged from 1.80 per 1,000 in Quebec to 3.50 per 1,000 in Atlantic Canada. Statistical modeling revealed no significant difference in the odds of MS amongst Quebec, BC, and Ontario. There have been no further national studies to validate these findings.

This study was limited by the narrow scope of the available data. We cannot accurately chart trends in the prevalence of MS across regions and over time. We were not able to calculate from the data the share of instances in which multiple DMD prescriptions were given to the same person, although this percentage should have been relatively consistent from year to year. We are therefore limited in our ability to assess the share of MS patients being treated with disease modifying therapy. A national registry of MS patients, with details of clinical status and treatment plan, would be very helpful in order to clarify the appropriateness of DMD prescription rates. 
Although it is possible that there was a small increase in the prevalence of MS in Canada in recent years, it is safe to assume that the $30 \%$ observed increase in DMD prescription rates far outstrips any such change in prevalence. Clinical trials published from 2002-2007 suggested that DMDs could be used in a larger patient population by virtue of their effectiveness after a first demyelinating event. Yet wide regional variations in prescription rates persisted and provinces tended to adhere to their original prescribing patterns in the period analyzed. The rules for DMD funding vary substantially between provinces and these differences threaten the concept of 'universality of access,' one of the pillars of the Canadian Medicare system.

\section{Conclusions}

As Jackevicius et al reasoned in a recent study on the use of lipid lowering agents, in the place of good comparative clinical evidence, differences in promotion and accessibility often become primary determinants of regional prescription patterns. ${ }^{19}$ We do not know how prescription rates are associated with outcomes in MS and what the "ideal" prescription rate would be. Medical interventions are not always benign and higher rates of therapy do not always correlate with better outcomes. ${ }^{20}$ This study however highlights the complex factors that may affect patient access. Patients' expectations, scientific evidence, industry influence, policy guidelines, and physician judgment all interact and play a role in regional treatment patterns. Further study is needed to determine the relative importance of these factors in the growth and interprovincial variability in DMD use in Canada.

\section{Disclosures}

Dr. Paul O'Connor has received either personal compensation (for consulting, serving on a scientific advisory board, or speaking) or financial support for scholarly activities from pharmaceutical companies that develop products for MS, including Biogen Idec., Sanofi-Aventis, EMD Serono, Abbott Labs, Teva Pharmaceuticals, Bayer, Bio MS, Genentech, Roche, and Novartis.

\section{REFERENCES}

1. Noseworthy JH, Lucchinetti C, Rodriguez M, Weinshenker BG. Multiple sclerosis. NEJM. 2000;343:938-52.

2. Mikol DD, Barkhof F, Chang P, Coyle PK, Jeffery DR, Schwid SR, et al. Comparison of subcutaneous interfereon beta-1a with glatiramer acetate in patients with relapsing multiple sclerosis (REGARD study): a mulicentre, randomised, parallel, openlabel trial. Lancet Neurol. 2008;7:903-14.

3. Goodin DS, Cohen BA, O'Connor P. Assessment: the use of natalizumab (Tysabri) for the treatment of multiple sclerosis (an evidence-based review): report of the Therapeutics and Technology Assessment Subcommittee of the American Academy of Neurology. Neurology. 2008;71:766-73.

4. O'Connor P, Devonshire V, Canadian Network of MS Clinics. The use of disease-modifying agents in multiple sclerosis - by the Canadian network of MS clinics. Can J Neurol Sci. 2008;35: 127-32.

5. Beck CA, Metz LM, Svenson LW, Patten SB. Regional variation of multiple sclerosis prevalence in Canada. Mult Scler. 2005;11: 516-9.

6. Noonan CW, Kathman SJ, White MC. Prevalence estimates for MS in the United Sates and evidence of an increasing trend for women. Neurology. 2002;58:136-8.
7. Berg J, Lindgren P, Fredrikson S, Kobelt G. Costs and quality of life of multiple sclerosis in Sweden. Eur J Health Econ. 2006;Suppl 2:S75-85.

8. Kobelt G, Berg J, Atherly D, Hadjimichael O. Costs and quality of life in multiple sclerosis: a cross-sectional study in the United States. Neurology. 2006;66:1696-702.

9. Imshealthcanada.com [homepage on the Internet]. Toronto: IMS Health Incorporated; c2009 [cited 2009 Oct 12]. Available from: http://www.imshealthcanada.com/.

10. Statcan.gc .ca[homepage on the Internet]. Ottawa: Statistics Canada; c2006 [updated 2008 Aug 21; cited 2008 Nov 13]. Available from: http://www12.statcan.ca/english/census06/.

11. Jacobs LD, Beck RW, Simon JH, Kinkel RP, Brownscheidle CM, Murray $\mathrm{TJ}$, et al. Intramuscular interferon beta-1a therapy initiated during a first demyelinating event in multiple sclerosis. NEJM. 2000;343(13):898-904.

12. Kinkel RP, Kollman C, O'Connor P, Murray TJ, Simon J, Arnold D, et al. IM interferon beta-1a delays definite multiple sclerosis 5 years after a first demyelinating event. Neurology. 2006;66(5): 678-84.

13. Goodin DS, Frohman EM, Garmany GP, Halper J, Likosky WH, Lublin FD, et al. Disease modifying therapies in multiple sclerosis. Report of the Therapy and Technology Assessment Subcommittee of the American Academy of Neurology and the MS Council for Clinical Practice Guidelines. February 2002.

14. Canadian Institute of Health Information. National survey of selected medical imaging equipment; 2003-2007.

15. The European Study Group on interferon beta-1b in secondary progressive MS. Placebo controlled multicentre randomized trial of interferon beta- $1 \mathrm{~b}$ in treatment of secondary progressive multiple sclerosis. Lancet. 1998;352(9139):1491-7.

16. Panitch H, Miller A, Paty D, Weinshenker B. North American Study Group on Interferon beta-1b in Secondary Progressive MS. Interferon beta- $1 \mathrm{~b}$ in secondary progressive MS: results from a 3-year controlled study. Neurology. 2004;63(10):1788-95.

17. Hauser SL, Johnston SC. Scripts for science: a new wrinkle on academic ties with industry. Ann Neurol. 2008;64(4):A13-5.

18. Warren SA, Svenson LW, Warren KG. Contribution of incidence to increasing prevalence of MS in Alberta, Canada. Mult Scler. 2008; $14: 872-9$

19. Jackevicius CA, Tu JV, Ross JS, Ko DT, Krumholz HM. Use of ezetimibe in the United States and Canada. NEJM. 2008;358: 1819-28.

20. Tu JV, Pashos CL, Naylor CD, Chen E, Normand S-L, Newhouse $\mathrm{JP}$, et al. Use of cardiac procedures and outcomes in elderly patients with myocardial infarction in the United States and Canada. NEJM. 1997;336(21):1500-5. 